CESIS Electronic Working Paper Series

Paper No. 367

Knowledge, innovation and space

\author{
Charlie Karlsson \\ Börje Johansson \\ Kiyoshi Kobayashi \\ Roger R. Stough
}

June, 2014 


\title{
Knowledge, innovation and space
}

\author{
Charlie Karlsson, CESIS, Jönköping International Business School, \\ charlie.karlsson@jibs.hj.se \\ Börje Johansson, CESIS, Jönköping International Business School, \\ borje.johansson@jibs.hj.se \\ Kiyoshi Kobayashi, Kyoto University \\ kobayashi.kiyoshi.6n@kyoto-u.ac.jp \\ Roger R. Stough, George Mason University \\ rstough@gmu.edu
}

\begin{abstract}
This paper provides an overview of relevant topics in contemporary research concerned with global, national, regional and local knowledge and innovation dynamics. In particular, we highlight how the global scene is changing in the contemporary world economy that we characterize as a knowledge economy. We show how knowledge and knowledge dynamics is driving innovation in the large urban agglomerations in the old and in new industrialized countries with their concentrations of abilities and resources and their superior intraregional and international geographical proximities. In relation to the large urban agglomerations we stress the role of (i) density and proximity externalities, (ii) the physical and cultural resource base of large cities, and (iii) the interactive dynamics related to learning and creativity.
\end{abstract}

Key-words: Knowledge, innovation, space, agglomeration, proximity, learning, creativity, social networks

JEL Codes: F6, O3, R11 


\section{INTRODUCTION}

The contemporary world economy - here referred to as a knowledge economy - is characterized by the ascendance of knowledge as a major factor of production and renewal. This evolution is accompanied by an increased mobility and liquidity of capital and associated regulatory and liberalization reforms of large dynamic international economic sectors such as finance, advanced business services and information industries. Recent technical advances and institutional innovations in transport and communications are not only reducing time distances and eroding the barrier of borders, but are also at the heart of the evolution of the world economy into a knowledge-rich global production system. We can observe the emergence of a new international division of labour, which takes shape through the formation of a global system of metropolitan and large urban regions, where each urban agglomeration offers expertise in various functions and activities and plays specific roles in the globalization process (Sassen, 2006). These cities are increasingly becoming dominating as (i) centres of political power, international trade, and the banking and financial system, (ii) centres that specialize in the creation, appropriation and dissemination of knowledge and innovations, (iii) centres where information is concentrated and transmitted through the media sector, and (iv) centres of creativity where the arts, culture and leisure activities are developed and consumed. They are today the main strategic hubs in the world economy as drivers of creativity, innovation and entrepreneurial activities, and, as a result, are the dominant engines of economic growth.

The global knowledge economy that has emerged in recent decades is not only characterized by rapidly increasing investments in education, and in particular higher education, software and $\mathrm{R} \& \mathrm{D}$; it is also characterized by other underlying fundamental structural changes (cf. Cooke et al., 2007):

1. Knowledge as an input in all kinds of production processes has become more important in terms of both quantity and quality.

2. Knowledge has become more important as a product, which is illustrated by the growth of knowledge-intensive business services and software and high technology industries.

3. Knowledge in the form of codified knowledge has become relatively more important than tacit knowledge, which is illustrated by the rapid expansion of science-based industries, such as biotechnology. ${ }^{1}$

4. Knowledge in the form of codified knowledge has become much more accessible due to the technological developments in and increased use of ICT. ${ }^{2}$

Today there is a widely spread acceptance that the displacement of old products and technologies by new ones in endogenously generated processes known as 'creative destruction' (Schumpeter, 1942) serves as the basic engine for economic growth and structural change. Innovation is the application in the market place of novel and improved products and processes. Innovation activities, which generate and diffuse new knowledge, have become major research topics in the contemporary knowledge-based economy. Innovation, which most often is the result of combinations of heterogeneous existing knowledge (Pavitt, 2005) achieved through continued interaction between firms and other organizations (Nelson, 1993) as well as between different individuals and departments within firms and organizations (Grant, 1996). This implies geographical and cultural proximity tends to play a critical role for achieving

\footnotetext{
${ }^{1}$ We think it is important to stress that this statement does not imply that tacit knowledge has become unimportant.

${ }^{2}$ This implies that the spatial diffusion speed of new codified knowledge has increased in recent decades.
} 
integration of diverse knowledge elements in innovation processes. The connection, interaction and cooperation between a variety of heterogeneous economic actors and sources of codified and tacit knowledge trigger creativity and, thus, allow for the development of new ideas, knowledge and technologies that could not have emerged in isolation. Several theoretical and empirical works claim that innovation depends on investments in knowledge as well as interactive learning and the circulation of ideas (Coe and Helpman, 1995; Rallet and Torre, 1999).

A significant characteristic of the current global structural transformation towards knowledge economies and knowledge societies is the changing nature of innovation processes. However, innovations are still very unevenly distributed between countries and regions, and tend to be clustered in certain locations (Feldman, 1994). Geographical space and the characteristics of locations play a decisive role in the myriad of underlying processes that enable and support the generation, diffusion, spillover, exploitation and application of new knowledge. Of course, the innovative capacity of locations depends on the characteristics of the local economic milieus, which over time are reshaped by general evolutionary processes (Frenken and Boschma, 2007). However, the innovative capacity of locations depends also on the external knowledge inputs through innovation network links to other locations (Bunnell and Coe, 2001), since innovation processes are increasingly dependent upon the conjunction of internal and external knowledge, which requires cooperation with a variety of economic agents often located in different places.

More than ever, innovation is about solving complex problems in multi-dimensional interactive and non-linear processes (Kline and Rosenberg, 1986; Malerba, 2005) under conditions of uncertainty, which makes it necessary to integrate highly specialized and globally distributed knowledge bases (Strambach and Klement, 2012) with a unique local knowledge base. Thus, innovating firms need to acquire knowledge from a variety of sources and economic actors at different spatial scales and to combine it with unique internal knowledge and competencies, which implies that they must build up, maintain and use different types of links for interaction and knowledge transfer. While addressing different facets of knowledge, innovation and space, this paper provides an overview of relevant topics in contemporary research concerned with global, national, regional and local knowledge and innovation dynamics.

\section{THE CHANGING GLOBAL SCENE}

Global markets with extensive outsourcing and 'just-in-time' deliveries are requiring strict timetables for on-time shipments of semi-manufactured products, components, spare parts and final goods between production, assembly and distribution centres scattered over the globe. As the 'half-life' of many new products in this knowledge economy becomes shorter and shorter, and the spatial distribution of supply and demand points adjusts rapidly in the system, what is transported, how it is transported, and to where and from where, are all changing. The emerging global knowledge economy is thus a distributed system with a vast array of geographically dispersed economic operations. People, knowledge, capital, goods and services are increasingly mobile and constitute, in the interactive milieu of the global economy, a large number of networks embracing scientific knowledge, technology, production, service, finance, culture and so on. Communications technologies have opened the door to systems of global commerce and network interdependencies but faster and more reliable transportation systems are needed to support them. Investments in transportation, therefore, not only allow existing patterns of business interactions to be carried out more efficiently but also support the evolution of new and radically different patterns of commerce at the global scale. 
The most critical nodes and links in the knowledge society are of course the knowledge networks through which transfer, diffusion and spillovers of knowledge take place. They are spatial networks - that is, they connect spatially diffused economic agents and localities - and consist of a set of knowledge nodes and a set of different knowledge links connecting them by means of transportation and communication and personal links. At a coarse spatial resolution, functional economic regions consisting of settlements such as towns, cities and metropolitan regions represent the knowledge nodes. These knowledge nodes are characterized by their endowments of knowledge production capacities and related activities, including knowledge infrastructures such as universities, meeting and interaction facilities, stocks of knowledge and human capital, local knowledge networks, and so on. Such knowledge nodes are often called clusters, which are geographic concentrations of firms and associated organizations that are highly networked and interdependent with each other both internally and externally. While clusters are not defined in terms of a specific geography, they are often coincident with more general urban concentrations - that is, cities and metropolitan areas.

At a finer geographical spatial scale, we have knowledge links within and between firms, research institutes and universities, and between individuals. The spatial perspective highlights the importance of spatial frictions as a factor limiting knowledge transfers and spillovers, and make it clear that excludability of knowledge is not only a result of patents, business secrets and so on, but also a consequence of limited physical accessibility and the time and money costs involved in spatial interaction (Karlsson and Nyström, 2011). In this picture of the global knowledge economy, we can identify a particular role played by intra-organization networks of multinational corporations (Almeida and Phene, 2012). In the context of the described economic transformation, transportation and communications technologies and infrastructures interact in complex ways. A superficial view holds that communications mostly substitute for transportation, as when a conference call, a video conference or exchange of documents via the Internet takes the place of a face-to-face meeting. However, the relationship is most often complementary. Preliminary interactions via electronic media eventually lead to an international shipment or passenger trip that would not have occurred otherwise. Furthermore, transportation and communication cannot be viewed as distinct processes. They are increasingly melded together, as in the cases of advanced logistical systems or intelligent transportation systems.

The transport and communication systems of today have evolved gradually alongside the development of trade and commerce, and the transformation of local, national and international markets. In today's globalized world, firms, cities and regions can only be competitive if the accessibility to the domestic and the international market is high enough. There exist major differences between locations as regards nodes of communication, services provided by the transport system and networking possibilities. This is problematic, since the transportation and communication systems serve as a medium for conveying information and knowledge, and for developing and introducing innovations. These systems foster economic progress and welfare, while being vehicles that facilitate relations and interactions between economic agents.

\section{KNOWLEDGE AND KNOWLEDGE DYNAMICS}

Knowledge exhibits very specific properties that are not shared by most other goods. Codified scientific and technological knowledge, such as published research results, patent applica- 
tions, etc., have a public good character, since they are neither non-rival nor non-excludable. Thus, knowledge is available for whoever searches for it (Arrow, 1962) and can be utilized by many different users without any reduction of its utility as an input in future research. It is certain that knowledge accessibility varies among different locations. Furthermore, the transfer of knowledge within and in particular between locations is associated with costs and time delays also in a world where the use of ICT is widely diffused. Interaction processes among individuals within firms and other organizations, such as universities, are central to the generation and use of knowledge and its transformation into innovations with economic value added. Treating knowledge as the key resource for innovation shifts the focus from the innovation itself to the process of knowledge generation, transformation and diffusion - that is, to knowledge dynamics (Crevoisier and Jeannerat, 2009), which emerge through the interactions of individuals within firms and other organizations and within networks of firms and other organizations. Location and space are the two main dimensions that shape the knowledge micro-dynamics behind innovations. Locations are not equal and their economic milieu are shaped by evolutionary economic processes (Feldman and Kogler, 2010) that involve cumulative processes (Myrdal, 1957) with concentration of economic activities in space generating location-specific advantages, not the least of these being knowledge-driven micro-dynamics.

The emergence of urbanization economies in larger urban agglomerations spurs diversity and variety, which foster cross-fertilization of knowledge and technologies. There are, in particular, three factors that influence local knowledge dynamics in a generic way: (i) the specific knowledge base of economic agents; (ii) the competencies and capabilities of the economic agents (Dosi et al., 2008); and (iii) the context of the local economic milieu. The cumulative aspects of knowledge implies that the generation of new knowledge builds upon currently existing knowledge (Antonelli, 2005), which suggests that local knowledge dynamics are path-dependent.

Thus, what an economic agent and a location have done and experienced in previous time tends to govern the type of new knowledge developed and the direction of innovation processes as well as the ability to absorb new knowledge developed elsewhere (Patel and Pavitt, 1997). Organizational routines and organizational capabilities, which are the result of localized learning processes, are essential factors that govern, coordinate and integrate knowledge exploitation and knowledge exploration (Teece, 2010) within the framework provided by existing local institutions and social capital. However, cumulative knowledge dynamics are complemented by a combinatorial knowledge dynamics focused on the use of spatially separated knowledge bases (which are accessed by means of outsourcing) and offshoring of knowledge-intensive business service activities and R\&D activities within global knowledge networks (Miozzo and Grimshaw, 2005; Guinet and De Backer, 2008). This implies that the spatial boundaries of knowledge used and generated in the innovation processes of economic agents can differ significantly according to the time distance to face-to-face contacts, knowledge and markets that are conducive to innovation (Andersson and Karlsson, 2005; McCann, 2007). Thus, different firms and different types of innovation activities require different types and levels of face-to-face interaction and will therefore chose to locate in different types of locations in relation to major metropolitan regions (Doloreaux and Shearmur, 2012), as firm-level innovation is impacted by a variety of slowly changing local cultural, institutional and economic factors (Moulaert and Sekia, 2003). Face-to-face interaction may promote innovation by increasing the possibilities of formal knowledge transfers and informal knowledge spillovers between firms and individuals (McCann and Simonen, 2007; Krugman, 1991). It achieves that by increasing (i) the mutual transparency of competitor behaviour and thereby competitor responses, (ii) the levels of co-operation between firms and individuals as 
well as the level of competition between firms, and (iii) the inter-firm mobility of labour, where the latter represents both a clear mechanism for knowledge spillover and capacitybuilding based on a recruitment strategy.

\subsection{Knowledge, Innovation and Agglomeration}

It is well established that innovation exhibits strong geographical clustering in locations where specialized inputs, services and resources for innovation processes are located (Asheim and Gertler, 2005). The importance of local input factors and of local inter-firm dynamics for a firm's ability to innovate and to gain competitive advantage is well documented in the literature on innovation and regional development (Wolfe, 2009). Thus, location and spatial concentration of firms that stimulate flows of knowledge between firms and between universities and firms and interactive learning are critical aspects of firms' efforts to generate new knowledge and innovations, not least because knowledge continues to be tied to certain locations (Liu et al., 2013). Multinational firms take advantage of this by locating in those concentrations (clusters) in the world that have accumulated specific competencies and knowledge that is difficult to acquire elsewhere (Lewin et al., 2009), which gives opportunities to fully exploit the interaction between intra-and inter-firm knowledge networks (Coe et al., 2008).

The initial foundations for understanding the microeconomic dynamics behind the agglomeration of innovation activities was laid by Marshall (1920). However, the analysis of the innovation-space relationship was renewed in the early 1990s with the launching of the so-called 'new economic geography'. A basic element of this relationship concerns the geographical reach of knowledge 'spillovers'. Krugman (1991), focusing on pecuniary externalities, disregards geographical knowledge externalities. However, at the same time, the role of innovation and processes of knowledge externalities linked to the diffusion of knowledge in growth dynamics is an essential element in modern theories of endogenous growth. But a synthesis of new economic geography and endogenous growth theory brings the two perspectives together and generates a formalized analytical framework for understanding localized growth dynamics based upon innovations (Baldwin and Martin, 2004), where technological externalities are central for explaining the spatial concentration of innovative activities.

Locations that benefit from substantial technological spillovers become more dynamic in terms of innovation and preferred locations for economic agents involved in innovation activities. Since these technological externalities are localized in space, those localities with even a slight technological head-start in a given technological field will accumulate knowledge in that field more rapidly than other locations. This, in turn, reduces the costs of innovation in such 'leader' localities, and thus attracts more resources for innovation and more economic agents involved in innovative activities in the pertinent technological field. The result is a cumulative agglomeration of $\mathrm{R} \& \mathrm{D}$ activities and innovative activities in this technological field in such localities.

The discussion above might be interpreted as if it is the clustering of $\mathrm{R} \& \mathrm{D}$ and innovation activities belonging to the same industry or to closely related industries in a location that determines the intensity of knowledge externalities and knowledge dynamics in the locality. This would imply that knowledge externalities are only transmitted in localities, where there exist a certain technological proximity between economic agents - that is, that the MAR externalities dominate (Marshall, 1920; Arrow, 1962; Romer, 1986). However, there are sub- 
stantial theoretical and empirical evidences pointing in the direction that it is the variety and diversity of activities in a locality - that is, the presence of many specialized clusters of activities including multiple supply chains supporting the specialized industry or industries among which knowledge can spill over - the so-called Jacobs externalities - that matter for innovation (Jacobs, 1969). Using a more dynamic approach, such as an innovation cycle, it is possible to illustrate that both types of knowledge externalities might be critical but at different phases of the cycle (Duranton and Puga, 2001). During the emerging, experimental phase of a new activity - that is, innovation - firms face many uncertainties concerning the most efficient production process and/or the most appropriate qualifications of its labour force. During this phase, then, firms will seek out diversified localities that offer proximity to other firms in the experimental stage and to a diversified labour force. The need for a diversified environment ends once the firms have found the appropriate production procedure. Then they will opt for a change of location to a locality that specializes in their production and where the production costs are lower - that is, the choice of new location will be governed by the extent of the MAR externalities in different locations.

\subsection{Innovation, Ability and Resources}

Innovation ability is the 'ability to integrate, build, and reconfigure internal and external competences to address rapidly changing environments' (Teece et al., 1997, p. 516). Recent contributions to the resource-based view of the firm (Almeida and Phene, 2012) also suggest that firms generate innovations in a process that exploits knowledge inputs from the conjunction of internal and external knowledge sources (Cantwell and Zhang, 2012). Earlier contributions have tended to focus on either the internal properties of firms and how firm capabilities develop in an experience-based learning process (Klette and Kortum, 2004; Kortum, 2008) or the importance of the local and regional milieu of innovating firms in terms of providing options for knowledge flows and spillovers in different types of networks (Audretsch and Feldman, 1996; Feldman, 1999).

The resource-based view of the firm also assumes that different firms have different endowments on internal knowledge - that is, of scientific, technological and entrepreneurial knowledge - and different capacities to absorb external knowledge. They also differ in their capacity to discover, create, evaluate and exploit innovations - that is, to create new combinations out of existing scientific, technological and entrepreneurial knowledge - and thus to be drivers of change in markets. One important reason for capacity differences among firms is differences in the degree of integration in the personal, social and professional networks that are major conveyors of external knowledge.

The combination of internal knowledge and external knowledge is cumulated within individual firms into knowledge of firm routines, product attributes, customers' preferences in different markets for product attributes, and routines for how to organize innovation activities (Karlsson et al., 2009). When relying on their cumulated resource bases and associated knowledge assets, innovating firms are characterized by their capacity to exploit in-house knowledge in conjunction with both local and distant external knowledge sources (Johansson et al., 2013). It is obvious that the geographical proximity of firms to external knowledge affects the opportunities to acquire useful knowledge inputs to their innovation and renewal activities, since the larger the geographical distance between economic agents, the larger the costs for interaction. Thus, we can conclude that the larger the geographical distance between economic agents, the lower the likelihood that they will interact. 
Firms engaged in product innovation search both internally and externally for information and knowledge about product attributes, production routines and market conditions. It seems reasonable to assume that external knowledge is quite diversified, while internal knowledge might be very specialized. A particular aspect of the internal knowledge of firms is the education and experiences - that is, competencies - of their employees, which is critical for the capacity to absorb new knowledge (Cohen and Levinthal, 1990). The internal knowledge of firms also encompasses (i) know-how with regard to the orchestration of innovation efforts, (ii) experience about accession of external knowledge, (iii) know-how about approaches that facilitate the combination of internal and external knowledge, and (iv) experience from interaction with external knowledge handlers. Acquiring external knowledge is crucial for the success of firms, particularly in the creative and high technology industries (Pittaway et al., 2004).

In each location, firms can tap an external knowledge potential, which represents the richness of the knowledge opportunities of the location and which varies depending upon which industry the firms belong to. From the external knowledge potential, firms can find advice, purchase innovation support and establish innovation co-operation with other economic agents, and absorb general knowledge flowing around within the location. Many earlier studies have examined how aggregate knowledge sources and R\&D activities inside urban regions generate knowledge flows and spillovers ${ }^{3}$ via formal and informal (Saxenian, 1996; Keeble, 2000) knowledge networks and local 'buzz' (Bathelt et al., 2004; Storper and Venables, 2004) and affect innovation activities and innovation outcomes of other firms located in the region (Jaffe et al, 1993; Audretsch and Feldman, 1999). Not least, it is often argued that firms located in innovative clusters can benefit from other co-located economic agents who generate local knowledge spillovers (Audretsch and Feldman, 2004). The conclusion from these contributions is that knowledge flows and spillovers are spatially bounded. However, some knowledge flows and spillovers transcend cluster and regional borders, and recent literature has stressed that knowledge linkages at multiple spatial scales are important (Bathelt et al., 2004; Torre, 2008). Johansson et al. (2013) illustrate how one intra-regional and one inter-regional knowledge potential can be calculated for each location and used in empirical analyses.

\section{KNOWLEDGE, INNOVATION AND PROXIMITY}

The convergence of increasing personal mobility and exchange of ideas, and growing interactions among diverse knowledge networks - made possible by the innovations and structural change in transport and communications - underlie the accelerating knowledge productivity and creativity as expressed in the production of new and improved economic, social and cultural goods and services. The continued growth of knowledge productivity depends thus on providing incentives that promote increasing ability for interaction among people in various knowledge networks ranging from the local to the global level - that is, with varying degrees of geographical proximity. Interestingly, our understanding of the determinants on knowledge flows, including so-called knowledge spillovers, is still limited and many researchers seem not to have understood the implications of the second law of economic geography (Prager and Thisse, 2012), namely that what happens close to us is often more important than what happens far from us. This misunderstanding is clearly demonstrated by, for example, Mattes

\footnotetext{
${ }^{3}$ Knowledge spillovers occur when knowledge created (or possessed) by one local economic agent is accessed and used by other economic agents without market interaction and financial compensation for the owner of this knowledge.
} 
(2012). She remarks that proximity is not a purely spatial phenomenon, but also includes organizational, institutional, social and cognitive dimensions.

However, even acknowledging that proximity is a multi-dimensional and multi-faceted concept, it is obvious that organizational, institutional, social and cognitive proximities are all to a certain extent functions of prevailing geographical proximities. Spatial frictions limit even the interactions within the same organization. This implies, for example, that relational proximity can never be a substitute for spatial proximity as claimed by Amin and Cohendet (2004). Relational proximity is, among other things, a function of the degree of spatial proximity. Spatial proximity works via cognitive, organizational, social, institutional and other proximities, but is not a substitute or a complement to other proximities as claimed by Boschma (2005). Cognitive proximity implies that economic agents that share the same knowledge base can exchange information about new knowledge more easily and in a less costly fashion. Organizational proximity implies that knowledge can be more easily transferred between economic agents because it reduces uncertainty and incentives for opportunistic behaviour. Social proximity reflects social ties, which lowers transaction costs for economic agents who want to share knowledge and cooperate on knowledge generation. Institutional proximity implies that the transmission of knowledge between economic agents is more efficient if they share a common institutional framework.

Certainly, these different proximities are important for the interaction and co-operation between firms involved in knowledge generation and innovation but the extent of these nongeographic proximities is all a function of the time distances between the actual economic agents, since what is at heart here is the interaction between individuals and economic agents. Spatial proximity per se is of no value. Its value comes from the interactions, the co-operation, the learning, and the contacts that it makes possible (Strambach and Klement, 2012). For example, cognitive proximity has to do with relations between individuals and the value of such a relation increases with a decreasing time distance between the individuals. Individuals in close geographical proximity often share the same local culture, the same institutional milieu and social practices, which contribute to a certain degree of cognitive proximity, which facilitates effective interaction and communication and the development of a mutual understanding. Torre (2009) highlights the importance of time distances between economic agents in this context.

\section{KNOWLEDGE, INNOVATION AND INTERACTION}

In principle, there are two ways to simplify and stimulate interaction between economic agents and the exchange of associated information and knowledge (Johansson and Quigley, 2004). The first is the so-called proximity advantage, which occurs because the frequency of face-to-face interaction between economic agents increases as the time distances between their locations decreases. This implies that an innovating firm benefits from being located in a regional economic milieu with rich and diverse knowledge flows and with a multiplicity of relevant knowledge sources like R\&D-intensive firms, research universities, knowledge-intensive business services, importers of knowledge-intensive products, etc., which can be accessed via face-to-face interaction. Face-to-face interaction is critical, since much (new) knowledge has a tacit nature - that is, it has a local 'stickiness' (von Hippel, 1994) and it is embedded in individuals (Gertler, 2003). ${ }^{4}$ Thus, its economic value is in most instances diffi-

\footnotetext{
${ }^{4}$ The transfer of tacit knowledge is facilitated by high levels of trust, and low cultural and/ or cognitive distance, including a common language and a shared scientific field (Gertler, 1995).
} 
cult to evaluate (von Egeraat and Kogler, 2013) without rather intense face-to-face interaction. The relative importance of different mechanisms for local knowledge transfer and spillovers is still hotly debated (see the literature references in Huber, 2012).

The second way to facilitate the transfer and exchange of knowledge including tacit knowledge between economic agents is investments in economic links including knowledge links between economic agents. Thus, an economic agent can invest in links and entire interaction networks with other (distant) economic agents to reduce the spatial frictions and the costs of communication of longer distances and thereby create a network advantage. This implies that when a proximity solution of the need to access external knowledge in a given location does not exist, an economic agent can choose to stay in the location and instead invest in links to more distant economic agents (such as suppliers, customers, knowledge-intensive business firms, industry associations, and research universities) as a means to compensate for the lack of feasible proximity options. Analyses of knowledge networks can lead to a better understanding of knowledge generation, innovation and general regional economic development (Ter Wal and Boschma, 2008).

In many cases, investments in long-distance links complement investments in links for shortdistance interaction. Economic agents have a double-link investment advantage of being located in an urban and in particular in a large urban agglomeration: (i) the need for lumpy investments is smaller in an urban agglomeration; and (ii) interaction links are at the same time easier to establish inside urban agglomerations. In particular, when two economic agents are located in the same functional region, the costs of forming interaction links should generically be smaller than when the same economic agents are more distant from each other due to the high density of knowledge-generating activities in urban agglomerations (Scott, 2006). This is the sin qua non value of being located in industrial clusters and functional regions.

\section{KNOWLEDGE, INNOVATION AND URBAN REGIONS}

Large urban regions, and in particular metropolitan regions, offer better conditions for knowledge generation and innovations than smaller regions due to the presence of strong and competitive businesses, appropriate research and education facilities, labour markets with a large and varied supply of qualified labour, well-developed infrastructures and supportive policy environments. They also function as major knowledge hubs in different global innovation networks (Chaminade and Vang, 2008). In particular, there are four factors that explain why large urban regions offer better conditions for innovation (Doloreaux and Shearmur, 2012): (i) they host several dynamic industrial clusters, especially in knowledge-intensive industries; (ii) they offer superior access to knowledge and technology flows and spillovers (Gilbert et al., 2008); (iii) they offer an economic milieu where firms can benefit from various positive externalities; and (iv) they enable intensive and diverse exchanges of unstructured, complex and tacit knowledge (Tödtling and Trippl, 2005).

The role of large cities for knowledge generation and innovation can be understood by applying a 'systems economics' approach (Antonelli, 2011) focusing on three particular and distinct systems features (Stough et al., 2011):

1. Density and proximity externalities, which are of particular importance due to the high degree of concentration of socio-economic and cultural advantages in large cities including (i) their large and diversified pool of skilled labour and knowledge handlers, 
(ii) their concentration of ICT infrastructure, (iii) their agglomeration economies that reduce the interaction and transaction costs for individuals and firms, and (iv) their role as major nodes for knowledge transfers and spillovers, which generates an economic milieu conducive for knowledge generation, innovation and entrepreneurial activities

2. The physical and cultural resource base of cities, which includes not only transport and communication infrastructures and their gateway functions but also their agglomerations of immaterial knowledge networks and their cultural capital.

3. Interactive dynamics related to learning and creativity, which are increasingly the 'intangibles' in the form of institutions, culture and high degree of internal mobility of capital, codified capital and human capital that large cities offer and that are factors driving the economic growth in large cities. Learning here means the capacity to adapt to rapidly changing competitive circumstances, which requires institutional openness, dynamism and flexibility.

\section{KNOWLEDGE, INNOVATION AND SOCIAL CAPITAL}

Social capital underlies any kind of social organization, and, for more than a decade, social capital has been a key concept in analyses of society, in particular at the local and the regional level (Karlsson, 2012). The supply of social capital varies substantially between different locations, and these supply differences bring about differences with regard to knowledge transfer and spillovers, knowledge generation and innovation. Social capital plays essential roles to foster networking and it contributes to understanding the inter-actability among people and social entities. Social capital refers to the formal and informal institutions and relationships, plus the values, attitudes and norms that shape the quality and quantity of a society's social interactions. A broader understanding of social capital accounts for both the positive and negative aspects it creates by including vertical as well as horizontal associations between people, and includes behaviour within and among organizations, such as firms, non-governmental organizations and politically governed bodies. The social and institutional context in locations functions to varying degrees as an enabling and supportive factor for interactive learning processes, knowledge exchange and innovation (Edquist, 2005).

The importance of social capital for innovation stems from its capacity by nurturing trust and shared values to (i) reduce local frictions - that is, local monitoring and transaction costs considerably in market transactions in local economic systems, and (ii) encourage all forms of local non-market interactions. Local frictions are reduced in at least three ways (Malecki, 1998, p. 11):

- the creation of a system of general reciprocity;

- the establishment of information channels, providing sorted and evaluated information and knowledge, so-called 'buzz' (Storper and Venables, 2004); and

- the simplification of market transactions through norms and sanctions by which economic exchanges can be facilitated, bypassing costly and legalistic institutional arrangements associated with market transactions.

In line with Thornton and Flynn (2003), one can assume that social capital affects innovation at three different levels: (i) social network ties between individuals; (ii) social network ties connecting teams and groups: and (iii) social network ties connecting firms and industries. Social networks make an important contribution to innovation, considering that such networks with cohesion in which trust is fostered are contexts in which information flows easily and 
provide characteristics that are central to reducing the risks of investments in knowledge and innovation. Social network ties also provide individuals and organizations with access to knowledge and other resources that are critical for innovation (Napahiet and Ghoshal, 1998), but, as stressed by Granovetter (1973), not all social ties are equally valuable.

\section{Concluding remarks}

In this paper we have provided an overview of relevant topics in contemporary research concerned with global, national, regional and local knowledge and innovation dynamics. In particular, we have highlighted how the global scene is changing in the contemporary world economy that we characterize as a knowledge economy. We have also shown how knowledge and knowledge dynamics is driving innovation in the large urban agglomerations in the old and in new industrialized countries with their concentrations of abilities and resources and their superior intra-regional and international geographical proximities. In relation to the large urban agglomerations we have stressed the role of (i) density and proximity externalities, (ii) the physical and cultural resource base of large cities, and (iii) the interactive dynamics related to learning and creativity.

\section{REFERENCES}

Almeida, P. and A. Phene (2012), Managing Knowledge Within and Outside the Multinational Corporation, in Andersson, M., B. Johansson and C. Karlsson (Eds), Innovation and Growth: From R\&D Strategies of Innovating Firms to Economy-Wide Technological Change, Oxford: Oxford University Press, pp. 21-37.

Amin, A. and P. Cohendet (2004), Architectures of Knowledge: Firms, Capabilities, and Communities, Oxford: Oxford University Press.

Andersson, M. and C. Karlsson (2005), The Role of Accessibility for the Performance of Regional Innovation Systems, in Karlsson, C., P. Flensburg and S.- $\AA$. Hörte (Eds), Knowledge Spillovers and Knowledge Management, Cheltenham: Edward Elgar, pp. 283-319.

Antonelli, C. (2005), Models of Knowledge and Systems of Governance, Journal of Institutional Economics, 1, 51-73.

Antonelli, C. (2011), The Dynamics of Knowledge Externalities: Localized Technological Change in Italy, Cheltenham: Edward Elgar.

Arrow, K.J. (1962), Economic Welfare and the Allocation of Resources for Inventions, in Nelson, R.R. (Ed.), The Rate and Direction of Innovative Activity, Princeton, NJ: Princeton University Press, pp. 609-625.

Asheim, B.T. and M.S. Gertler (2005), Regional Innovation Systems and the Geographical Foundations of Innovation, in Fagerberg, J., D. Mowery and R.R. Nelson (Eds), Oxford Handbook of Innovation, Oxford: Oxford University Press, pp. 291-317.

Audretsch, D.B. and M.P. Feldman (1996), R\&D Spillovers and the Geography of Innovation and Production, American Economic Review, 86, 630-640.

Audretsch, D.B. and M.P. Feldman (1999), Innovation in Cities: Science-Based Diversity, Specialization and Localized Competition, European Economic Review, 43, 409-429.

Audretsch, D.B. and M.P. Feldman (2004), Knowledge Spillovers and the Geography of Innovation, in Henderson, J.V. and J.-F. Thisse (Eds), Handbook of Urban and Regional Economics, Amsterdam: North Holland, 2713-2739. 
Baldwin, R.E. and P. Martin (2004), Agglomeration and Regional Growth, in Henderson, J.V. and J.-F. Thisse (Eds), Handbook of Regional and Urban Economics, vol. 4, Amsterdam: Elsevier, pp. 2671-2711.

Bathelt, H., A. Malmberg and P. Maskell (2004), Clusters and Knowledge: Local Buzz, Global Pipelines and the Process of Knowledge Creation, Progress in Human Geography, 29, 31-56.

Boschma, R.A. (2005), Proximity and Innovation: A Critical Assessment, Regional Studies, $39,61-74$.

Bunnell, T.G. and N.M. Coe (2001), Spaces and Scales in Innovation, Progress inHuman Geography, 25, 569-589.

Cantwell, J. and F. Zhang (2012), Knowledge Accession Strategies and the Spatial Organization of R\&D, in Andersson, M., B. Johansson and C. Karlsson (Eds), Innovation and Growth: From R\&D Strategies of Innovating Firms to Economy-Wide Technological Change, Oxford: Oxford University Press, pp. 88-111.

Chaminade, C. and J. Vang (2008), Globalization of Knowledge Production and Regional Innovation Policy: Supporting Specialized Hubs in the Bangalore Software Industry, Research Policy, 37, 1684-1696.

Coe, D.T. and E. Helpman (1995), International R\&D Spillovers, European Economic Review, 39, 859-887.

Coe, N.M., P. Dicken and M. Hess (2008), Introduction: Global Production Networks - Debates and Challenges, Journal of Economic Geography, 8, 267-269.

Cohen, W.M. and D.A. Levinthal (1990), Absorptive Capacity: A New Perspective on Learning and Innovation, Administrative Science Quarterly, 35, 128-152.

Cooke, P., C.P. Laurentis, F. Todtling and M. Tirppl (2007), Regional Knowledge Economies: Markets, Clusters and Innovation, Cheltenham: Edward Elgar.

Crevoisier, O. and H. Jeannerat (2009), Territorial Knowledge Dynamics: From Proximity Paradigm to Multi-Location Milieus, European Planning Studies, 17, 1223-1241.

Doloreaux, D. and R. Shearmur (2012), Collaboration, Information and the Geography of Innovation in Knowledge Intensive Business Services, Journal of Economic Geography, 12, 79-105.

Dosi, G., M. Faillo and L. Marengo (2008), Organizational Capabilities, Patterns of Knowledge Accumulation and Governance Structures in Business Firms: An Introduction, Organizational Studies, 29, 1165-1185.

Duranton, G. and D. Puga (2001), Nursery Cities: Urban Diversity, Process Innovations and the Life-Cycle of Products, American Economic Review, 91, 1454-1477.

Edquist, C. (2005), Systems of Innovation: Perspectives and Challenges, in Fagerberg, J., D.C. Mowery and R.R. Nelson (Eds), The Oxford Handbook of Innovation, Oxford: Oxford University Press, pp. 181-208.

Feldman, M.P. (1994), The Geography of Innovation, Boston: Kluwer.

Feldman, M.P. (1999), The New Economics of Innovation, Spillovers and Agglomeration - A Review of Empirical Studies, Economics of Innovation and New Technology, 8, 5-25.

Feldman, M.P. and D. Kogler (2010), Stylized Facts in the Geography of Innovation, in Hall, B.H. and N. Rosenberg (Eds), Economics of Innovation, Amsterdam: Elsevier, pp. 411427.

Frenken, K. and R.A. Boschma (2007), A Theoretical Framework for Evolutionary Economic Geography: Industrial Dynamics and Urban Growth as a Branching Process, Journal of Economic Geography, 7, 635-649.

Gertler, M.S. (1995), "Being There": Proximity, Organization, and Culture in the Development and Adoption of Advanced Manufacturing Technologies, Economic Geography, $71,1-26$. 
Gertler, M.S. (2003), Tacit Knowledge and the Economic Geography of Context, or the Undefinable Tacitness of Being (There), Journal of Economic Geography, 31, 75-99.

Gilbert, B.A., P.P. McDougall and D.B. Audretsch (2008), Clusters, Knowledge Spillovers and New Venture Performance: An Empirical Examination, Journal of Business Venturing, 23, 405-422.

Granovetter, M. (1973), The Strength of Weak Ties, American Journal of Sociology, 78, 1360-1380.

Grant, R. (1996), Toward a Knowledge-Based Theory of the Firm, Strategic Management Journal, 17, 109-122.

Guinet, J. and K. De Backer (in cooperation with P. Teirlinck and A. van der Zwan) (2008), The Internationalization of Business $R \& D$ : Evidence, Impacts and Implications, Paris: OECD.

Huber, F. (2012), Do Clusters Really Matter for Innovation Practices in Information Technology? Questioning the Significance of Technological Knowledge Spillovers, Journal of Economic Geography, 12, 107-126.

Jacobs, J. (1969), The Economy of Cities, New York: Random House.

Jaffe, A.B., M. Trajtenberg and R. Henderson (1993), Geographic Localization of Knowledge Spillovers as Evidenced by Patent Citations, The Quarterly Journal of Economics, 108, 577-598.

Johansson, B., S. Johansson and T. Wallin (2013), Internal and External Knowledge - Innovation of Export Varieties, CESIS Working Paper No. 297, Centre of Excellence for Science and Innovation Studies, Stockholm and Jönköping.

Johansson, B. and J.M. Quigley (2004), Agglomeration and Networks in Spatial Economies, Papers in Regional Science, 83, 165-176.

Karlsson, C. (2012), Entrepreneurship, Social Capital, Governance and Regional Economic Development: An Introduction, in Karlsson, C., B. Johansson and R.R. Stough (Eds), Entrepreneurship, Social Capital and Governance: Directions for the Sustainable Development and Competitiveness of Regions, Cheltenham: Edward Elgar, pp. 1-26.

Karlsson, C. and K. Nyström (2011), Knowledge Accessibility and New Firm Formation, in Desai, S., P. Nijkamp and R.R. Stough (Eds), New Direction in Regional Economic Development: The Role of Entrepreneurship Theory and Methods, Practice and Policy, Cheltenham: Edward Elgar, pp. 174-197.

Karlsson, C., R.R. Stough and B. Johansson (2009), Introduction: Innovation and Entrepreneurship in Functional Regions, in Karlsson, C., R.R. Stough and B. Johansson (Eds), Entrepreneurship and Innovations in Functional Regions, Cheltenham: Edward Elgar, pp. 1-20.

Keeble, D. (2000), Collective Learning Processes in European High-Technology Milieux, in Keeble, D. and F. Wilkinson (Eds), High-Technology Clusters, Networking and Collective Learning in Europe, Aldershot: Ashgate, pp. 199-229.

Klette, T.J. and S. Kortum (2004), Innovating Firms and Aggregate Innovation, Journal of Political Economy, 112, 986-1018.

Kline, S.J. and N. Rosenberg (1986), An Overview of Innovation, in Landau, R. and N. Rosenberg (Eds), The Positive Sum Strategy: Harnessing Technology for Economic Growth, Washington, DC: National Academy Press, pp. 275-305.

Kortum, S. (2008), Exploring Innovation with Firm-Level Data, The Conferene Board, Economics Program Working Paper Series 08-11.

Krugman, P. (1991), Geography and Trade, Cambridge, MA: MIT Press.

Lewin, A.Y., S. Massini and C. Peeters (2009), Why Are Companies Offshoring Innovation: The Emerging Global Race for Talent, Journal of International Business Studies, 40, 901-925. 
Liu, J., C. Chaminade and B. Asheim (2013), The Geography and Structure of Global Innovation Networks: A Knowledge Base Perspective, European Planning Studies, 21, 118.

Malecki, E.J. (1998), How Development Occurs: Local Knowledge, Social Capital and Institutional Embeddedness, paper presented at the Annual Meeting of Southern Regional Science Association, Savannah, GA.

Malerba, S. (2005), Sectoral Systems: How and Why Innovation Differs Across Sectors, in Fagerberg, J., D. Mowery and R.R. Nelson (Eds), The Oxford Handbook of Innovation, Oxford: Oxford University Press, pp. 380-406.

Marshall, A. (1920), The Principles of Economics, London: Macmillan.

Mattes, J. (2012), Dimensions of Proximity and Knowledge Bases: Innovation between Spatial and Non-Spatial Factors, Regional Studies, 46, 1085-1099.

McCann, P. (2007), Sketching Out a Model of Innovation, Face-to-Face Interaction and Economic Geography, Spatial Economic Analysis, 2, 117-134.

McCann, P. and J. Simonen (2007), Innovation, Co-operation, and Labour Mobility, in Arauzo-Carod, J.M. and M.C. Manjón-Antolín (Eds),

Entrepreneurship, Industrial Location and Economic Growth, Cheltenham:

Edward Elgar, pp. 335-330.

Miozzo, M. and D. Grimshaw (2005), Modularity and Innovation in Knowledge-Intensive Business Services: IT Outsourcing in Germany and the UK, Research Policy, 34, 14191439.

Moulaert, F. and F. Sekia (2003), Territorial Innovation Models: A Critical Survey, Regional Studies, 37, 289-302.

Myrdal, G. (1957), Economic Theory and Underdeveloped Regions, New York: Duckworth.

Napahiet, J. and S. Ghoshal (1998), Social Capital, Intellectual Capital, and the Organizational Advantage, Academy of Management Review, 23, 242-266.

Nelson, R.R. (Ed.) (1993), National Innovation Systems: A Comparative Analysis, Oxford: Oxford University Press.

Patel, P. and K. Pavitt (1997), The Technological Competencies of the World's Largest Firms: Complex and Path-Dependent, but Not Much Variety, Research Policy, 26, 141156.

Pavitt, K. (2005), Innovation Processes, in Fagerberg, J., D.C. Mowery and R.R. Nelson (Eds), The Oxford Handbook of Innovation, Oxford: Oxford University Press, pp. 86114.

Pittaway, L., M. Robertson, K. Munir, D. Denyer and A. Neely (2004), Networking and Innovation: A Systematic Review of the Evidence, International Journal of Management Reviews, 5 (3-4), 137-168.

Prager, J.-C. and J.-F. Thisse (2012), Economic Geography and the Unequal Development of Regions, London: Routledge.

Rallet, A. and A. Torre (1999), Is Geographical Proximity Necessary in the Innovation Networks in the Era of the Global Economy, GeoJournal, 49, 373-380.

Romer, P. (1986), Increasing Returns and Long Run Growth, Journal of Political Economy, 94, 1002-1037.

Sassen, S. (2006), Cities in the World Economy, London: Sage Pine Forge.

Saxenian, A.L. (1996), Regional Advantage: Culture and Competition in Silicon Valley and Route 128, Cambridge, MA: Harvard University Press.

Schumpeter, J. (1942), Capitalism, Socialism and Democracy, New York: Harper.

Scott, A.J. (2006), Entrepreneurship, Innovation and Industrial Development: Geography and the Creative Field Revisited, Small Business Economics, 26, 1-24. 
Storper, M. and A.J. Venables (2004), Buzz: Face-to-Face Contact and the Urban Economy, Journal of Economic Geography, 4, 351-370.

Stough, R.R., R.J. Stimson and P. Nijkamp (2011), An Endogenous Perspective on Regional Development and Growth, in Kourtit, K., P. Nijkamp and R.R. Stough (Eds), Drivers of Innovation, Entrepreneurship and Regional Dynamics, Berlin: Springer, pp. 3-20.

Strambach, S. and B. Klement (2012), Cumulative and Combinatorial Micro-Dynamics of Knowledge: The Role of Space and Place in Knowledge Integration, European Planning Studies, 20, 1843-1866.

Teece, D.J. (2010), Technological Innovation and the Theory of the Firm: The Role of Enterprise-Level Knowledge, Complementarities, and (Dynamic) Capabilities, in Hall, B.H. and N. Rosenberg (Eds), Handbook of the Economics of Innovation, Amsterdam: Elsevier, pp. 679-730.

Teece, D.J., G. Pisano and A. Shuen (1997), Dynamic Capabilities and Strategic Management, Strategic Management Journal, 18, 509-533.

Ter Wal, A. and R.A. Boschma (2008), Applying Social Network Analysis in Economic Geography: Theoretical and Methodological Issues, Annals of Regional Science, 43, 739756.

Thornton, P.H. and K.H. Flynn (2003), Entrepreneurship, Networks and Geographies, in Acs, Z.J. and D.B. Audretsch (Eds), Handbook of Entrepreneurship Research: An Interdisciplinary Survey and Introdution, London: Kluwer, pp. 21-34.

Tödtling, F. and M. Trippl (2005), One Size Fits All? Towards a Differentiated Regional Innovation Policy Approach, Research Policy, 34, 1203-1219.

Torre, A. (2008), On the Role Played by Temporary Geographical Proximity in Knowledge Transmission, Regional Studies, 42, 869-889.

Torre, A. (2009), Retour sur la Notion de Proximité Géographique, Géographie, Économie, Société, 11, 63-75.

von Egeraat, C. and D.F. Kogler (2013), Global and Regional Dynamics in Knowledge Flows and Innovation Networks, European Planning Studies, 21, 1-6.

von Hippel, E. (1994), Sticky Information and the Locus of Problem Solving: Implications for Innovation, Management Science, 40, 429-439.

Wolfe, D. (2009), Introduction: Embedded Clusters in the Global Economy, European Planning Studies, 17, 179-187. 